\title{
PECULIARITIES OF RESTORATION OF WORKING PARTS OF DRILLING BIT MATRIX BODIES
}

\author{
B.V. STEFANIV, V.F. KHORUNOV, O.M. SABODASH, S.V. MAKSYMOVA and V.V. VORONOV \\ E.O. Paton Electric Welding Institute, NASU
}

11 Bozhenko Str., 03680, Kiev, Ukraine. E-mail: office@paton.kiev.ua

\begin{abstract}
Peculiarities of defects of worn-out matrix drilling bits, occurred during service, were considered. The degree of wear of working parts of seats under diamond-hard-alloy cutters was investigated. Methods of preparation of worn-out areas of working parts for their restoration by arc surfacing were optimized. It is shown that to restore the defective areas of crosspieces of holes of diamond-hard-alloy cutters of body blades, alloy of Kh20N80 grade was recommended as the best one, while TeroCote 7888T alloy was the best one for hole substrates. It was found that protective coating TeroCote 7888T deposited on alloy VK10, provides the most effective protection from erosive and abrasive wears. Basing on the obtained data, the technology of restoration of working parts of blades of matrix bit bodies has been developed. These bits after their restoration were transferred to the customer and at present they are passing the industrial trials at the enterprise of the Poltava region in drilling gas and oil wells. 7 Ref., 4 Figures.
\end{abstract}

Key words: drilling matrix bits, superhard materials, microstructure, protective coating, wear resistance, arc surfacing, hardness

The competitiveness of modern gas-and-oil production enterprises depends mainly on efficiency and reliability of the industrial equipment being used. The efficiency of any drilling equipment or industrial complex is determined by a number of technological breaks or emergency stops for a scheduled on emergency repair.

This is connected to the largest degree with a wear of a drilling tool. The service life of drilling tool depends on the service life of all the working parts included into it. The drilling tool subjected to intensive wear (abrasive, erosion wear, cavitation, impact, pressure, etc.) has, as a rule, a short-time term of service, that reduces greatly the total service life of the tool and leads to the scheduled stops. The expenses, connected with the replacement of drill tool and standstill of equipment, are transformed into multimillion losses for enterprise.

The extension of life of the used rock destruction tool can be attained by applying the technology of restoration of working parts of bit bodies, surfacing of protective wear-resistant coating, that makes it possible to bring the worn-out bits to the condition of new ones.

The main task of present work was to evaluate the degree of wear of bit matrix bodies, equipped with polycrystalline diamond cutters (PDC) and restoration of the worn-out working parts.

The objects of investigations were the tools for rotational method of drilling, i.e. PDC matrix bits for a continuous drilling. The body of matrix bit is made of composite material on tungsten carbide base, possessing higher wear resistance, as compared with steel one, and allowing drilling of abrasive rocks at a higher speed. The working parts of the matrix bit are equipped mainly with PDC of the leading manufacturers: Genesis, Smith Bits, Element Six Series (XT, HRC, HOT, SQC, GDC, etc.), and calibrating surfaces are made of hard alloys of B25 and B35 grades of SANDVIK Coromant production (Sweden) (analogs of domestic hard alloys VK6 and VK8, respectively).

To restore the worn-out matrix drilling bits, an experience of repair of working parts of steel bits was applied [1]. But the repair of matrix bodies is more complicated due to a poor weldability and problems in surfacing of hard alloys.

Technology of restoration of drilling bits, used for drilling of oil and gas wells by surfacing consumables [2-4], which are produced abroad and used in Ukraine, can be classified by a shape of manufacture and method of surfacing:

- manual surfacing with electrodes;

- arc surfacing with wear-resistant flux-cored wire;

- semi-automatic or automatic surfacing using solid wire, flux-cored wire, self-shielding fluxcored wire;

- gas-flame surfacing and spraying with alloys (surfacing powders);

- plasma surfacing and spraying;

- laser surfacing;

- induction surfacing; 

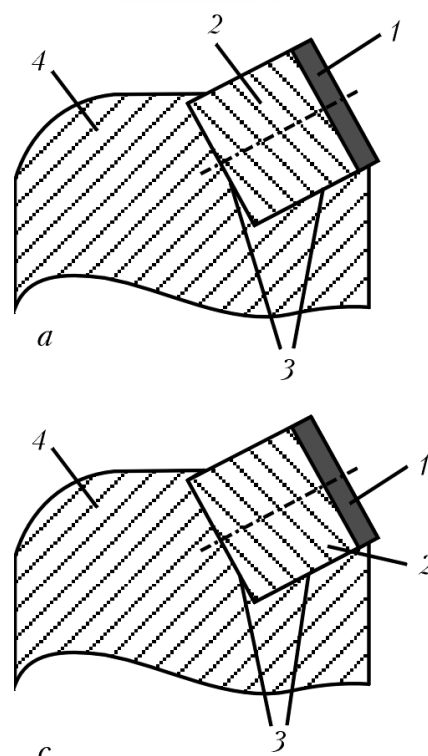

Figure 1. Schemes of wear of seat surfaces for matrix bit cutters: $a$ - non-worn-out seat; $b, c$ - repairable seat (wear of seat surface 10-30\%); $d$ - seat not subjected to restoration (wear of seat surface for more than $30 \%$ ) ; 1 diamond plate; 2 - tungsten-carbide substrate; 3 - seat surface for PDC; 4 - matrix bit body

- electroslag surfacing;

- electron beam surfacing.

In Ukraine only during the recent years the centers for repair and restoration of bits for continuous drilling and recovery of core began to be developed. In 2012 the specialists of enterprise «DP Service» (Poltava) mastered the new technology of repair of drilling bits of company «Polycrystalline Diamond Bits», which allows restoring the PDC bits with steel and matrix body.

In accordance with data [5] the market price of the new PDC-bit of $215.9 \mathrm{~mm}$ diameter is 15,000-40,000 USD. The cost of its restoration is different depending on character of damage and varied from 1,000 up to 10,000 USD, but

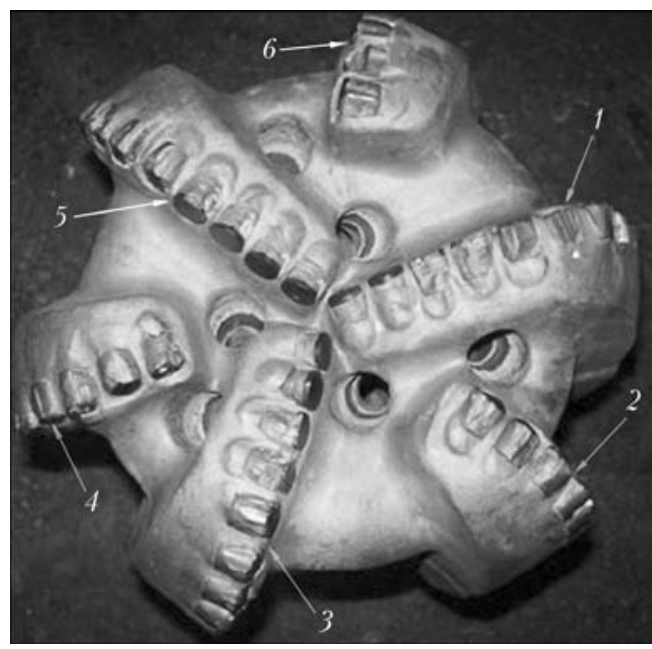

Figure 2. Appearance of seat wear and working parts of areas of matrix bit of $311.1 \mathrm{~mm}$ diameter due to the possibility of multi repairs of one and the same bit, the customer can obtain the restored tool, which has a service life of that of the new one only for $10-30 \%$ of its cost. On average one bit, as to their opinion, can be restored 3-5 times. But the repair of bits depends not only on the replacement of diamond-hard-alloy cutters (DHC) of working parts, but also, in the first turn, on degree of wear of working areas of layers of tungsten-carbide matrix of seats for DHC ( $\mathrm{Fi}^{-}$ gure 1). If the working parts of the bit matrix body are worn out by more than $30 \%$, then the given bit cannot be restored because of a small thickness of tungsten-carbide matrix layer. From different estimations of the world manufacturers of matrix bits the thickness of tungsten-carbide matrix is from 5 up to $50 \mathrm{~mm}$ depending on the type and design.

Some features of restoration of bits with an abrasive wear are shown on the example of repair of worn-out working parts of two drilling matrix bits of $311.1 \mathrm{~mm}$ of «Smith Bits» production (USA).

The total life of one of these bits was $800 \mathrm{~m}$. During examination of degree of wear of the working parts of six blades the areas with a plane abrasive wear of base metal and body core with damage of seats in a central region and negligible wear on the bit calibrating surface were observed. The most serious defect of damaged central region of the bit blade is wear of base metal of substrate of the working part (Figure 2), where DHCs are fixed into holes by brazing method. Due to the fact that the bit body was manufactured of the matrix material, which is characterized by the increased wear resistance, the works were carried out for determination of criteria of repairability for restoration of worn-out working parts of the given bit.

Let us take for example the fourth blade of the bit being examined, which has a wear both of substrate of seats around the perimeter of cutter and also crosspieces between them (Figure 3). The cause of this wear occurrence was the insufficient wear and impact resistances of the cutters, cooling of washing channels, as well as occurring rupture vibrations of bit in the well. In the given case the wear of seats and crosspieces between the seats was from 0.1 up to $5.0 \mathrm{~mm}$ on all the bit six blades.

Final evaluation of the given bit wear [6] according to Classification System, accepted by the International Association of Drilling Contractors (IADC) is 37 RO T $0 \mathrm{I}$ (CT, BT, WT, FC) PR, i.e. «repairable». Basing on the results of our works for the creation of technological regulation 
of repair of drilling bits of different assortment with DHC [1,7], the investigations were carried out for the selection of method of deposition and material, which would correspond to all the physical-chemical properties of metal of the bit matrix body. To attain the aim, the properties of existing wear-resistant materials and technologies of restoration were investigated in this work, and methods of deposition of interlayers and protective coatings on the worn-out areas of damaged parts were developed.

To deposit the protective and wear-resistant layers of hard-alloy plates of VK10 grade, two methods of surfacing were investigated: manual argon-arc tungsten-electrode, and gas-flame (oxy-acetylene). And during deposition of protective coatings on defective areas of the working parts the arc surfacing was preferred. In the first turn, this is connected with difficulties of restoration of crosspieces between the blade holes and substrate of cutters, where DHCs are fixed. It is impossible in gas-flame surfacing to deposit bead of 3-5 $\mathrm{mm}$ thickness on the worn-out crosspiece because of possible fusion of its very thin layer by the torch flame, while in arc surfacing it is real to deposit a layer on the same worn-out area at keeping the optimum conditions.

During restoration of worn-out parts of the bit body the investigations for selection of material, which could correspond to physical-chemical properties of metal of the bit matrix body, were carried out. The optimizing of arc surfacing technology was performed on non-standard hardalloy specimens: 1 - alloy VK10 + TeroCote 7888T; 2 - alloy VK10 + PANCh-11 + TeroCote 7888T; 3 - alloy VK10 + alloy of Kh20N80 grade; 4 - alloy VK10 + PANCh-11.

For surfacing of intermediate and protective coating on mock-up specimens the inverter welding machine «Korall-300» was used. The set optimum conditions of surfacing with the least heat inputs were: $U=10-12 \mathrm{~V}$ and $I=60-120$ A. The obtained thickness of the deposited layer was in the range of $1-3 \mathrm{~mm}$.

From the results of the carried out investigations two materials for restoration of defective areas of working parts were selected. The first one is TeroCote $7888 \mathrm{~T}$, which provides a good wetting $\gamma$ the hard alloy and has no defects in surfacing the protective coating of substrates and perimeters of DHC holes. The second one is alloy of Kh20N80 grade, which is designed for restoration of thin crosspieces of holes, which, in its turn, contributes to a good machining of seats after surfacing and retains the geometry of holes for DHC fixation.

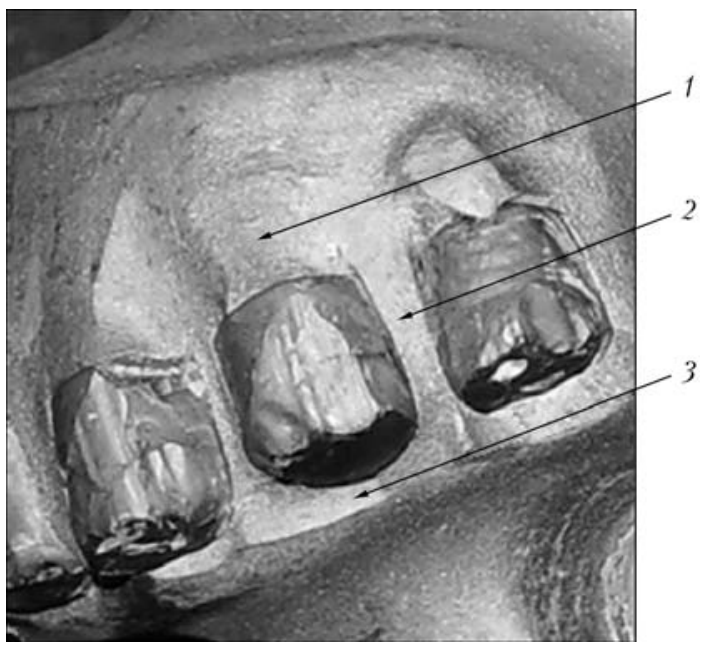

Figure 3. Scheme of wear of working part: 1 - seat substrate; 2 - seat crosspiece; 3 - perimeter of seat for DHC

Results of investigations were used in restoration of working parts of body blades of two worn-out matrix drilling diamond bits of $311.1 \mathrm{~mm}$ diameter. For example, at the area (Figure $4, a$ ) after unbrazing of DHCs from the holes the works were carried out on machining of damaged areas of blade holes, i.e. wear of substrates and DHC crosspieces before repair was up to $30 \%$ of the working part wear. For the restoration of worn-out crosspieces and substrates of DHC with the bit body the method of arc surfacing was used at a low heat input for reducing the level of residual stresses in the de-
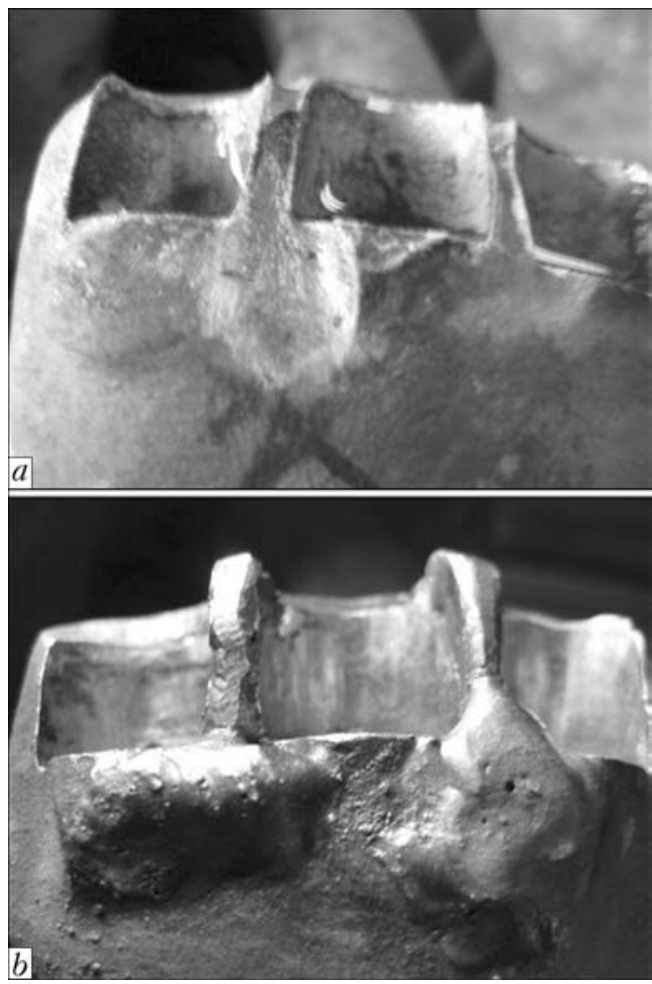

Figure 4. Appearance of worn-out part of blade after DHC unbrazing $(a)$ and after surfacing of DHC crosspieces and substrates $(b)$ 

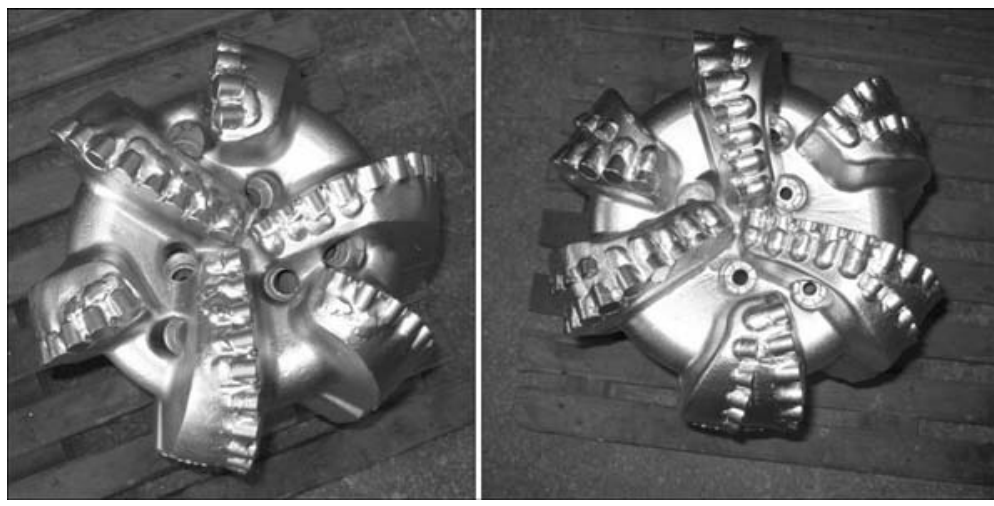

Figure 5. Appearance of matrix drilling bits of $311.1 \mathrm{~mm}$ diameter after restoration

posited layers (Figure 4, $b$ ). As a filler for restoration of crosspieces, the wire of $1.0 \mathrm{~mm}$ diameter of grade Kh20N80 was used. The optimum welding conditions of welding were $U=10-12 \mathrm{~V}$ and $I=60-100$ A. For surfacing the DHC substrates, the protective wear-resistant material TeroCote 7888T (Castolin) of $5.0 \mathrm{~mm}$ diameter was used. Here, the surfacing conditions were $U=10-12$ Vand $I=80-120$ A.

The produced structure of the deposited metal provides a high hardness (HRC 43-49) of the surfacing zone and very effective protection from wear in drilling of medium and hard rocks. The applied method of increasing the wear resistance by using protective material TeroCote $7888 \mathrm{~T}$ allows increasing significantly the service life of the restored areas of working parts of drilling bit bodies, operating in severe conditions of the erosion-abrasive wear.

Figure 5 shows drilling bits of $311.1 \mathrm{~mm}$ diameter after restoration of working parts. The described bits were tested in the Poltava region during drilling of gas wells.

\section{Conclusions}

1. Basing on the carried out investigations the challenging compositions of protective coatings were selected providing a good wetting of hardalloy material ( $\mathrm{WC}-\mathrm{Co}$ ) and good hardness at abrasive and erosion wear of the drilling bits.

2. Technology of deposition of interlayers and protective coating can be applied also for restoration of other defective areas of working parts of matrix bodies of the drilling bits for a continuous drilling.

3. Results of investigations can be used in mining and other branches of industry of Ukraine.

1. Stefaniv, B.V., Khorunov, V.F., Sabadash, O.M. et al. (2014) Features of reconditioning steel drill bit watercourse. The Paton Welding J., 11, 50-54.

2. Materials for brazing and surfacing TeroCote: http: / www.castolin.com.ua/

3. Surfacing materials BAT-Servis: http://www. btrans.com.ua/qw/id/79/

4. Surfacing alloy relite of L3 type: http://www.resource@aranei.com

5. DP Service repaired 13 drill bits of KUBGAZ: http: / / www.dp-service.com.ua/ru/nefterynok-magazine

6. Khorunov, V.F., Stefaniv, B.V., Sabadash, O.M. et al. (2012) Peculiarities of wear and criteria of repairability of drill bits with diamond-hard-alloy cutters. The Paton Welding J., 10, 39-43.

7. Khorunov, V.F., Stefaniv, B.V., Sabadash, O.M. et al. (2012) Specifics of repair technologies of drill bits with diamond-hard-alloy cutters. In: Transact. on results obtained in 2010-2012, 488-493. Kiew: PWI.

Received 08.04.2015 